\title{
Bioremediation of Sludge using Pseudomonas aeruginosa
}

\author{
Rajveer Kaur $^{1 *}$, Gurjot Kaur Mavi ${ }^{2}$ and Shweta Raghav ${ }^{3}$ \\ ${ }^{1}$ CT Institute of Pharmaceutical Sciences Jalandhar, India \\ ${ }^{2}$ Department of Animal Genetics and Breeding, ${ }^{3}$ Department of Veterinary Anatomy, \\ GADVASU Ludhiana, India \\ *Corresponding author
}

\begin{tabular}{|c|c|}
\hline & A B S T R A C T \\
\hline $\begin{array}{l}\text { Bioremediation, } \\
\text { Pseudomonas } \\
\text { aeruginosa, } \\
\text { Sludge }\end{array}$ & \multirow{3}{*}{$\begin{array}{l}\text { For the bioremediation of sludge, samples were collected from different places } \\
\text { near Jalandhar city of the Punjab (India). In order to analyze the sludge, the } \\
\text { physiochemical parameters like } \mathrm{pH} \text {, Moisture and heavy metal are determined. } \\
\text { The bacterial strain Pseudomonas aeruginosa was screened for the removal of } \\
\text { heavy metal like LEAD and COPPER from the industrial sludge. The effect on } \mathrm{pH} \\
\text { and moisture was determined. Maximum lead removal was noted to be } 0.20 \text { by } \\
\text { Pseudomonas aeruginosa species from the sludge sample and copper removal was } \\
\text { noted to be } 0.30 \text { by P. aeruginosa species. The present study depicts that the } \\
\text { bacterial species remove heavy metal from sludge and can be used for the } \\
\text { industrial waste management and other environmental maintenance. }\end{array}$} \\
\hline Article Info & \\
\hline $\begin{array}{l}\text { Accepted: } \\
\text { 04 March } 2019 \\
\text { Available Online: } \\
10 \text { April } 2019\end{array}$ & \\
\hline
\end{tabular}

\section{Introduction}

Bioremediation is the process of utilizing living organisms, microorganisms to degrade pollutants and contaminants from the environment and transform them into less toxic form. Bioremediation is based on the ability of a microorganism to degrade the hydrocarbons into components that can be taken up by other micro-organisms as a nutrient source or can be safely returned to the environment. Degraded organic components are converted into water, carbondioxide and other inorganic compounds. Not only microbes but plants too help in biodegradation of hydrocarbons. An effective bioremediation requires enzymatic attack by microorganisms to convert pollutants into harmless products. Environmental parameters should be optimum to help the microorganisms to grow and degrade the pollutants at a rapid rate (de la Cueva et al., 2016). There are limitations to this technology also, for example, chlorinated hydrocarbons or other high aromatic hydrocarbons are almost resistant to microbial degradation or are degraded at a really slow pace. But bioremediation techniques are somewhat economical and can be widely implemented. Most of the techniques in bioremediation are aerobic in nature, but anaerobic processes are also being developed to help degrade pollutants in oxygen deficit areas (Franchi et al., 2016). There are two 
types of bioremediation strategies: In Situ Bioremediation- This method of bioremediation is cost effective and causes less disturbance to the surrounding area of the contaminated site. In situ method is mainly used for soil contamination due to oil spills. Thus, it is limited by the depth up to which microorganisms can help degrade pollutants. Mostly upto 30-60 $\mathrm{cm}$ of depth in soil have been reached for the process of bioremediation. Bioventing- This is common in situ method of bioremediation which involves supplying air at a low flow rate and provides much-needed oxygen and nutrients by wells to stimulate the microorganisms in the contaminated site. Through this method, it is determined that volatilization of the contamination is avoided, and they do not spread. It is an effective method for simple hydrocarbons. In situ biodegradation- In this process oxygen and nutrients are added to the soil by means of an aqueous solution that circulates through the contaminated soil, the solution contains water-containing nutrients, oxygen and electron acceptors to stimulate the microorganism. This method is used for soil and groundwater treatment.

Ex-situ bioremediation- Biopiles- This is a combination of landfarming and composting. In this method engineered cells are constructed in composted piles in a wellaerated condition. Moreover, this technique is refined from land farming method and controls the spread of contamination by volatilization and leaching. This technique is used for treatment of contamination of the surface of spilled hydrocarbon pollutants mainly petroleum products. Biopiles helps grow indigenous aerobic and anaerobic microorganisms. Apart from biopiles, Land farming and composting are two other methods of Ex-situ bioremediation. Bioreactors- Bioreactors are used for treating hydrocarbon pollutants in a safe and simple way. It is used for ex situ bioremediation where slurry reactors or aqueous reactors are used for treating contaminated water or soil. The contaminants are kept in a containment vessel and using various apparatus mixing is done at a three-phase system that is, solid, liquid and gas. The slurry formed due to this mixing help the biodegradation of the pollutants and also increases the biomass (which contains the microorganisms). The only limitation of this technique is that the pretreatment that has to be done before the contaminated soil or water can be placed in the bioreactors (Vidali, 2001).

Bioremediation has been proven to be an effective, environmentally friendly and less expensive treatment option for remediation of aquifers contaminated with hydrocarbons (Shen and Wang, 1995; Jardine and Taylor, 1995; Ganguli and Tirupathi, 2002). Biotransformation is the process by which a highly toxic compound is converted to less toxic/no toxic compound using biological process. This process can be aerobic / anaerobic / anoxic or combination of these three, based on the microorganisms. It has been reported that several microorganisms, under various environmental conditions, can decontaminate the dam sediments very effectively.

This process depends on carbon source, $\mathrm{pH}$, temperature, dissolved oxygen, ORP, and presence of other oxyanions and metal cations (Chen and Hao, 1998). Bioremediation is the use of biological treatments, for the clean-up of hazardous chemicals in the environment. At present, employing the, biochemical abilities of microorganisms is the most popular strategy for the biological treatment of contaminated soils, sediments and waters (Head, 1998). Now a days, great emphasis is placed on environmental biotechnology and attaining sustainable development: in particular, biological techniques can be applied effectively in the remediation of 
sediments contaminated by organic pollutants from a variety of sources.

Bioremediation can be defined as a natural or managed biological degradation of environmental pollution. The indigenous microorganisms normally carry out bioremediation and their activity can be enhanced by a more suitable supply of nutrients and/or by enhancing their population. Therefore, this process exploits such microorganisms and their enzymatic activities to effectively remove contaminants from contaminated sites. This process is a cost effective means of cleanup of hydrocarbon spills from contaminated sites as it involves simple procedures only and it is an environmentally friendly technology which optimizes microbial degradation activity via control of the $\mathrm{pH}$, nutrient balance, aeration and mixing. Also, bioremediation is a versatile alternative to physicochemical treatments and produces non-toxic end products such as $\mathrm{CO} 2$, water and methane from petroleum hydrocarbons.

\section{In situ bioremediation}

The most effective means of implementing in situ bioremediation depends on the hydrology of the subsurface area, the extent of the contaminated area and the nature of the contamination. In general, this method is effective only when the subsurface soils are highly permeable, the soil horizon to be treated falls within a depth of $8-10 \mathrm{~m}$ and shallow groundwater is present at $10 \mathrm{~m}$ or less below ground surface.

\section{On site (ex site) bioremediation}

Here the contaminated soil is excavated and placed into a lined treatment cell. Thus, it is possible to sample the site in a more thorough and, therefore, representative manner. On site treatment involves land treatment or land farming

\section{Microorganism used for bioremediation}

Pseudomonas aeruginosa (ATCC NO.2453)

$\begin{array}{lc}\text { Kingdom } & \text { Bacteria } \\ \text { Phyllum } & \text { Proteobacterium } \\ \text { Class } & \text { Gamma Proteobacter } \\ \text { Order } & \text { Pseudomonadace } \\ \text { Family } & \text { Pseudomonadaces } \\ \text { Genus } & \text { Pseudomonas } \\ \text { Spcies } & \text { P.aeruginosa }\end{array}$

$\begin{array}{lll}\text { (STRAIN (ATCC 2453) rifampicin } & \end{array}$ Effluents released from textile industries contain various organic dyestuffs, chrome and other chemicals during various operations and produce a large quantity of solid and liquid waste containing hexavalent chromium, salts of zinc, sulfate, copper, lead. The treatment of these wastes is essential before discharging them to environment because of the toxicity and carcinogenicity. In trace amounts the lead is considered as essential nutrient but it is more carcinogenic and mutagenic at elevated level. It is also toxic to humans and plants. Conventional treatment technologies become less effective and more expensive when metal concentration are in form of 10 to $100 \mathrm{mg} / 1$. Non conventional technologies are proved to be effective in removal of metal under this range such as $99.9 \%$ of lead was removed in the $10 \mathrm{gm} / 1$ of lead solution.

However the conventional and less effective physico chemical method are being replaced by more effective biological methods such as biosorption for the removal of hexavalent lead from the aqous solution, biostimulation for the lead (V1), bioreduction for lead contamination in sludge and ground water bu the reducing bacteria which include the use of eco friendly and easy available material such as cocoa shells, peanut shells that are removed hexavalent lead activity. 
In the present study Pseudomonas aeruginosa strain is used for the removal of heavy metals like lead, copper, cadmium and chromium. This bacteria is found very effectively in bioremediation of heavy metal because metals are directly and indirectly involved in the all aspect of microbial growth metabolism. Bioremediation of heavy metal by bacterial cell has been recognized as potential alternative to existing technologies for the removal of heavy metal from the industrial waste. This study is an attempt to explore innovative, cost effective and environment friendly technology for the bioremediation of lead contamination using microorganisms.

\section{Materials and Methods}

For the bioremediation of lead sludge sample were collected from the dumping site and nearby area of textile industries.

\section{Analysis of sludge sample}

The physical chemical parameters ( $\mathrm{Ph}$, color, moisture, phosphorus and heavy metal like lead and copper) were determined. $\mathrm{Ph}$ is determined by electronic digital ph meter. Phosphorus was determined by the colorimeter. lead was determined by colorimeter and Copper was determined by colorimeter for metal analysis the effluent sample were digested with HNO3.

\section{Revival of lyophlized culture}

\section{From pre-scored ampules}

Disinfect the sample by wiping with $70 \%$ alcohol.

Wrap the scored area (arrow at the narrow neck below the gold colored band) with the ethanol dampened tissue to protect your fingers. The tissue should not so wet that alcohol enters the ampoule.

Bend and break the ampoule at the narrow, pre scored area. The alcohol damped tissue provides good cushioning and protection against cuts for this step.

Aseptically added $0.2-0.5 \mathrm{ml}$ of sterile water. Using a sterile pipette gently aspired the contents several times to mix the suspension thoroughly.

Let the suspension to rest for 15-30 minutes. Inoculate the suspension onto an appropriate medium and incubate.

\section{Results and Discussion}

The sample was taken from various drains surrounding Jalandhar and as well as from the dumping site of industries. Then they were analyzed for physico-chemical properties such as $\mathrm{pH}$, moisture content, phosphorus and heavy metal like lead and copper). The $\mathrm{pH}$ of the sludge was varied according to their origin ranging between 5.6 and 8.9. The ph was determined by using calibrated ph meter. The higher value of moisture and solid were observed in sample collected from Hamira and Kala sanghian drains. The bacterial cultures exhibited removal even at higher levels of lead and the bacterial growth decreased with increase in the metal concentration. Similarly, sludge samples were analyzed for heavy metals. Nine different bacterial species were screened on the basis of morphological characteristics which grew in $10-50 \mathrm{mg} / \mathrm{l}$ of lead concentration. After screening, Pseudomonas aeruginosa was found capable to remove lead and used for further study. It showed consistent growth, both in nutrient broth and nutrient. The data was observed for the uptake of metal ions vs contact time for different conc. The metal removal efficiency increased with increase in time. However, a remarkably increased in percent lead removal was estimated $75.0 \pm$ $2.27 \%$ by Pseudomonas species. Different concentration of both was used like $10 \mathrm{mg} / \mathrm{l}$, and $69.70 \pm 0.80 \%$ removal by Pseudomonas aeruginosa at 40mg/l and $90.88 \pm 0.87 \%$ by 
Pseudomonas aeruginosa. Pseudomonas aeruginosa removed considerable amount of lead and showed significant efficiency for bioremediation. From the above results it is observed that Pseudomonas aeruginosa can be used for the removal of lead from waste generated by industries. Further study can be carried out different concentrations and the strain can be selected for further removal of lead from effluent and sludge. $\mathrm{pH}$ of active sludge effluent was 8.0 and atmospheric temperature was $25^{\circ} \mathrm{C}$, while ambient temperature was $20^{\circ} \mathrm{C}$. Several mesophilic gram-negative and copper resistant bacteria were also isolated. The enrichment media showed better growth in comparison to direct culture method for the isolation of copper resistant bacteria and less time was taken by the organisms. Also, the isolates in primary enrichment method could grow on $6 \mathrm{mM}$ concentration of Copper containing medium.
Majority of the bacterial isolates were belonging to gram-negative non-fermentive Pseudomonas (4 isolates). One gram-negative coccus was also capable to grow on $2 \mathrm{mM}$ concentrations of Copper; but on subsequent inoculation, the strain lost its ability to grow on more than $2 \mathrm{ml}$ copper. The data obtained in this study clearly shows that with use of cadmium resistant mutated biomass, bioaccumulation of Copper solution considerably increased. P.aeruginosa one of the isolate was able to efficiently remove $94.7 \%$ in $30 \mathrm{mg} / \mathrm{L}$ of copper solution within 60 min. cadmium toxicity. Bio-chemical tests were performed to characterize microorganisms on basis of morphological and biochemical properties. The tests performed in the present study were Gram staining, Citrate utilization test, $\mathrm{H}_{2} \mathrm{~S}$ production, Nitrate reduction test, Indole test, Methyl red test, Voges-proskaeur test.

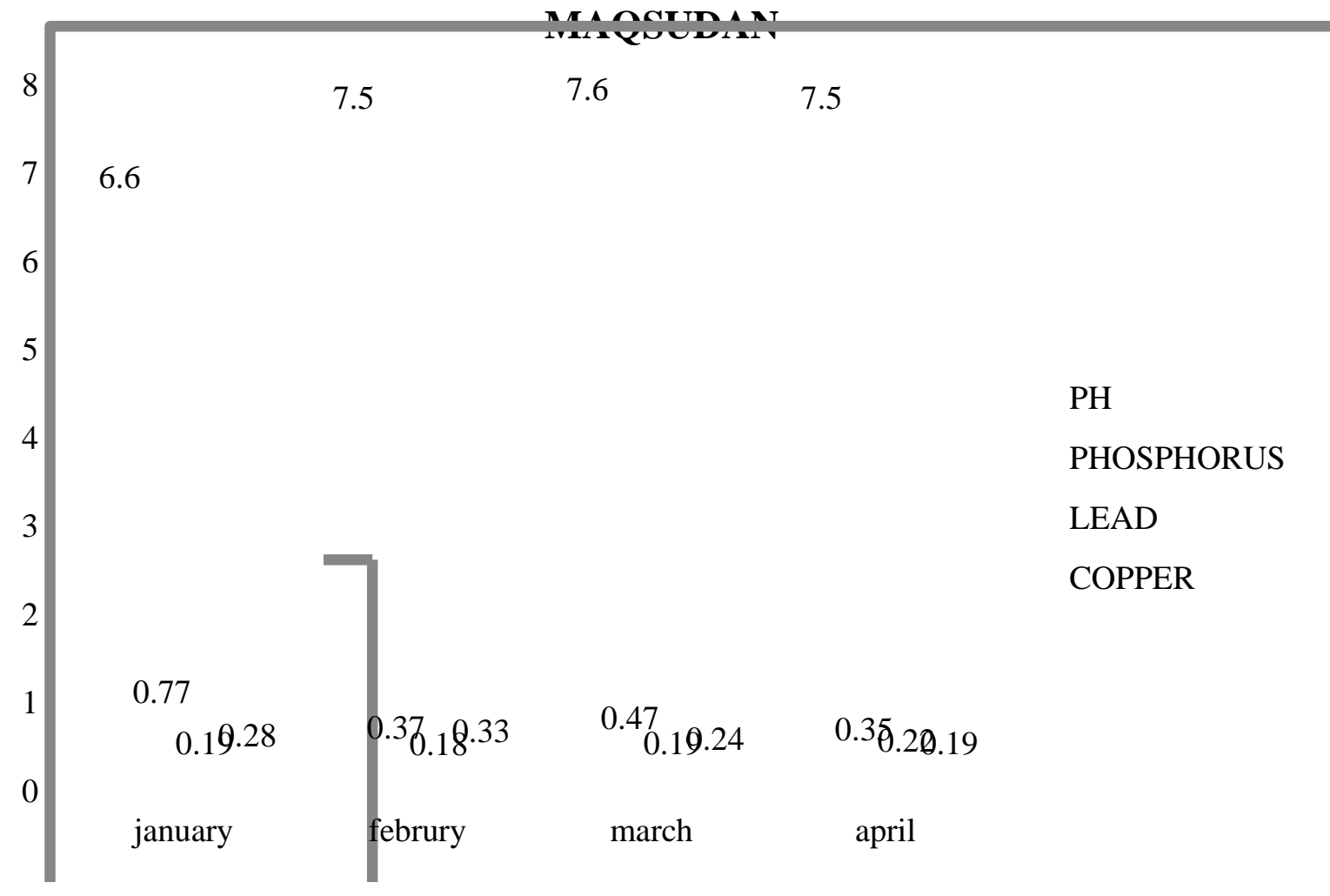


Int.J.Curr.Microbiol.App.Sci (2019) 8(4): 69-79
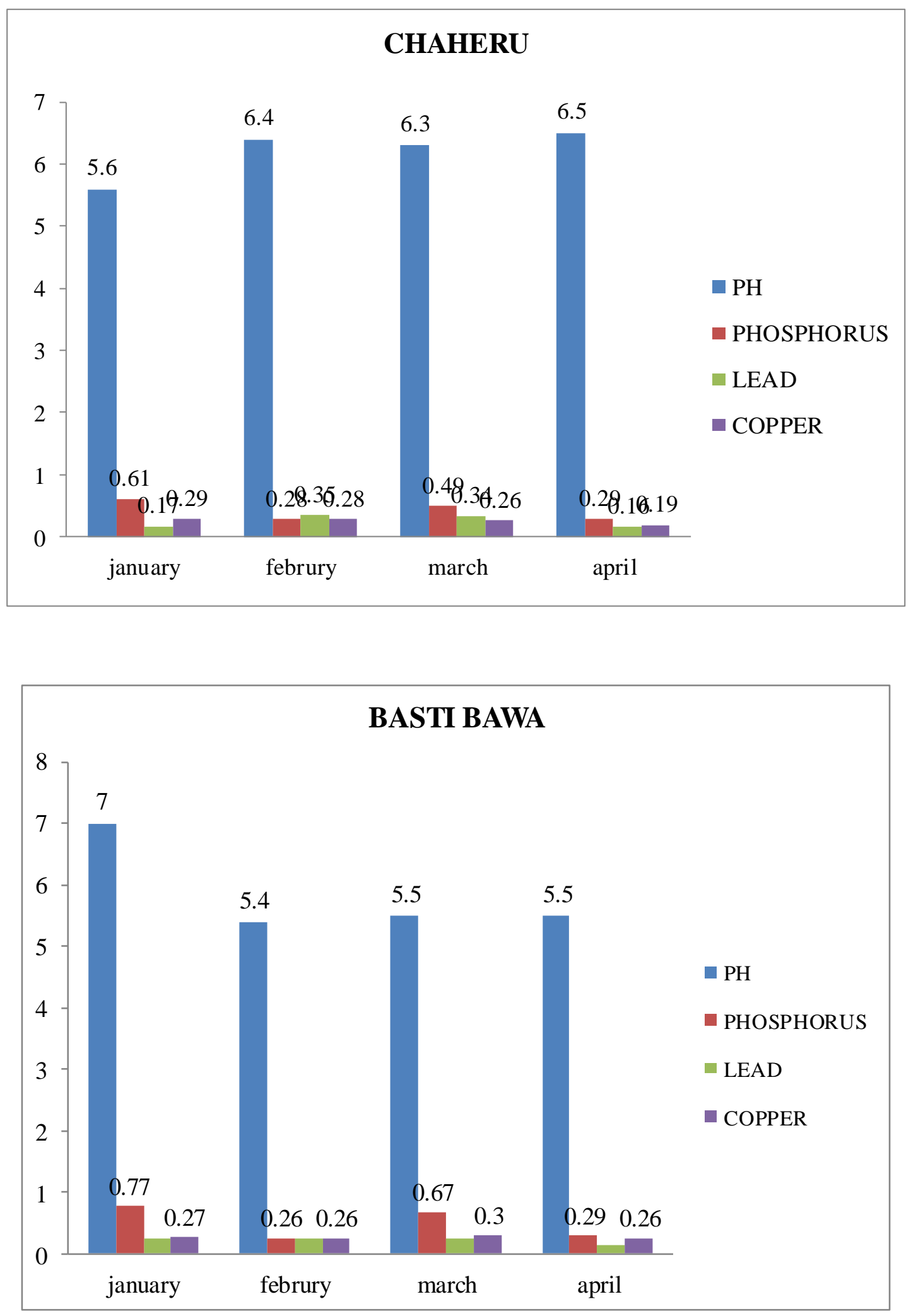

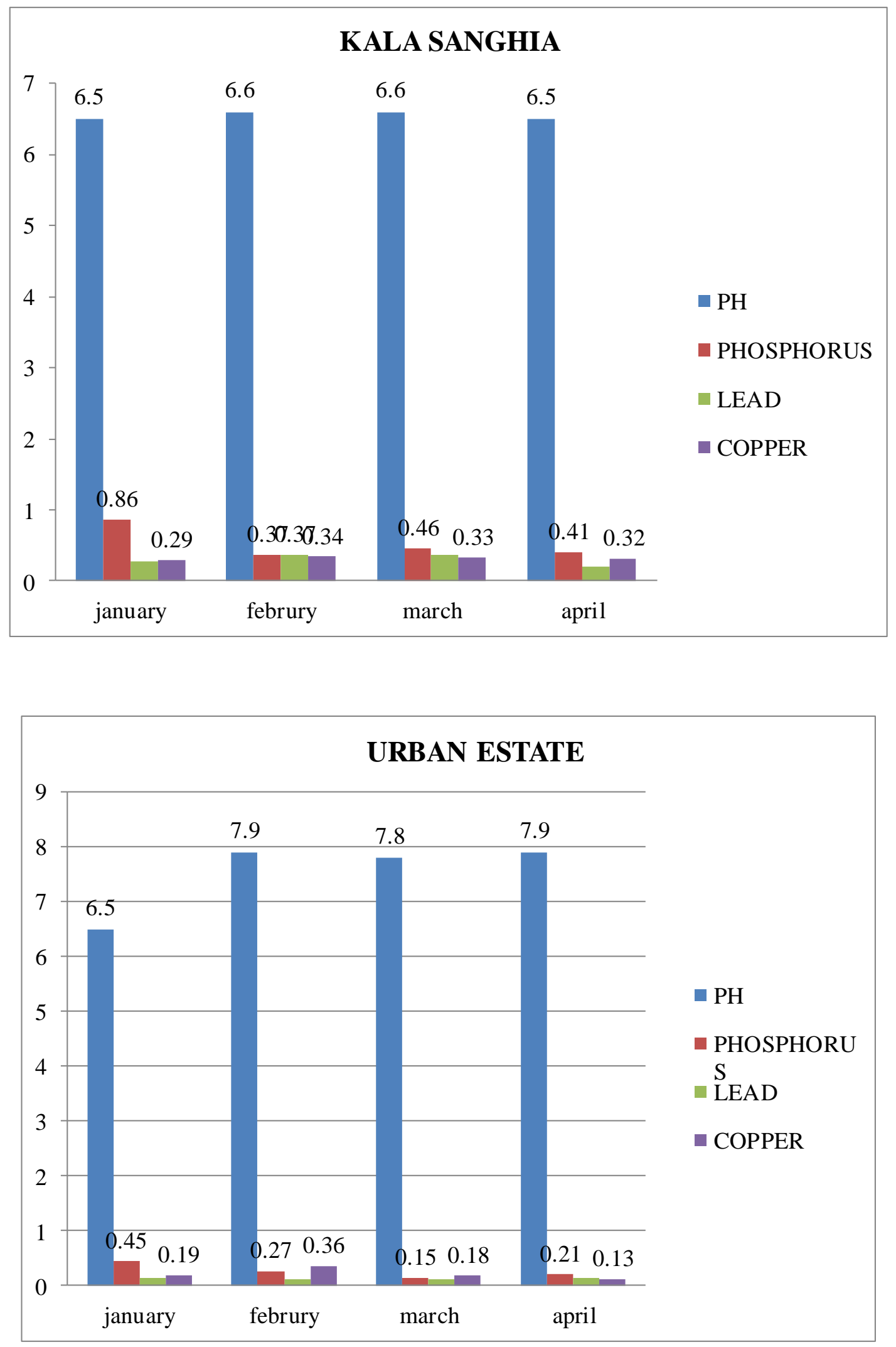


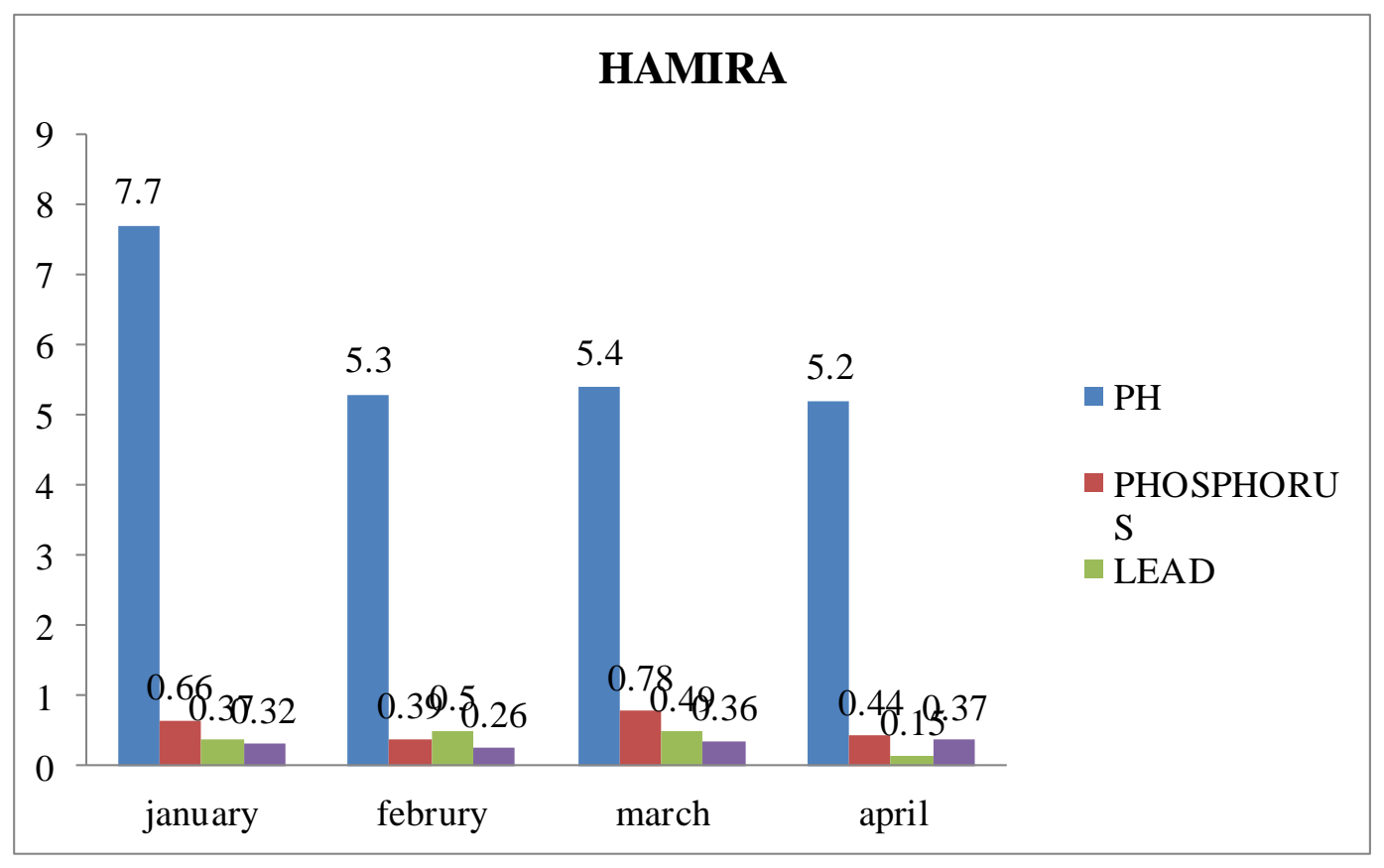

Oleszkiewicz et al., (1993) described the moisture content by dry method of sludge in which sludge drying is really a necessity, through discussing the results of sludge drying, the process of sludge drying.

Shiro Yoshizaki et al., (2000) worked on Principle and Process of Heavy Metal Removal from Sewage Sludge. The sufficient removal of heavy metals from sewage sludge remains to be achieved.

Hulsbeek et al., (2002) described a protocol for improving the quality and controllability of the simulation studies for activated sludge processes.

Zespół et al., (2004) explained about economical factors of sludge by using dry method. Sludge utilization options often indicate sludge drying as the best option.

Yang et al., (2005) discus about the potential adsorbent for phosphorus removal Alum sludge refers to the byproduct from the processing of drinking water in Water Treatment Works.
Zheng et al., (2009) described the Sludge Phosphorus Tests in Phosphorus is an essential element for plant growth and development, as it plays key roles in plant metabolism, structure and energy transformation.

Jabbari Nezhad Kermani et al., (2010) describe that Lead bioremediation by metalresistant mutated bacteria isolated from active sludge of industrial effluent in which Bioremediation of metal pollutants from industrial wastewater using metal resistant bacteria is a very important aspect of environmental biotechnology.

Wenyi Deng et al., (2010) reported on Moisture distribution in sludges based on different testing methods in which Moisture distributions in municipal sewage sludge and dyeing sludge and paper mill sludge were experimentally studied based on four different methods, i.e., drying test, thermogravimetric.

Krishnaveni et al., (2013) explained that bioremediation of steel industrial effluents using sludge microorganisms in which 
Bioremediation is treatment processes that uses naturally occurring microorganisms as well as plants to breakdown, or degrade hazardous substances into less toxic or non toxic substances.

Ghazali et al., (2004) investigated the bioremediation of hydrocarbon in contaminated soils by mixed cultures of hydrocarbon-degrading bacteria. The strains were selected based on the criteria that they were able to display good growth in crude oil, individual hydrocarbon compounds or both. Their ability to degrade hydrocarbon contamination in the environment was investigated using soil samples that were contaminated with diesel, crude oil 52 or engine oil.

Vezzulli et al., 2004 evaluated the potential of bioremediation for mobilisation of carbon in organic-rich sediments. Both bioaugmentation (bio-fixed microorganisms) and biostimulation (oxygen release compounds ORC) protocols had been tested and the response of the bacterial community has been described to assess the baseline for bioremediation potential.

Mrayyan and Battikhi (2005) described bioremediation as cost effective, environmentally friendly treatment for oily contaminated sites by the use of microorganisms. In their study, laboratory experiments were conducted to establish the performance of bacterial isolates in degradation of organic compounds contained in oily sludge from the Jordanian Oil Refinery plant. As a result of the laboratory screening, three natural bacterial consortia capable of degrading total organic carbons (TOC) were prepared from isolates enriched from the oil sludge.

Shuchi et al., (2006) tested the ability of three bacterial strains, Bacillus sp. SV9,
Acinetobacters., SV4 and Pseudomonas sp. SV17 from contaminated soil in Ankleshwar, India to degrade the complex mixture of petroleum hydrocarbons (such as alkanes, aromatics, resins and asphaltenes), sediments, heavy metals and water known as oily sludge.

Margesin et al., (2005) evaluated soil biological activities as a monitoring instrument for the decontamination process of a mineral oil contaminated soil was made using measurements of microbial counts, soil respiration, soil biomass and several enzyme activities

The sample was taken from various drains surrounding Jalandhar and as well as from the dumping site of industries. Then they were analyzed for physico-chemical properties such as $\mathrm{pH}$, moisture content, phosphorus and heavy metal like lead and copper). The $\mathrm{pH}$ of the sludge was varied according to their origin ranging between 5.6 and 8.9. The ph was determined by using calibrated ph meter. The higher value of moisture and solid were observed in sample collected from Hamira and Kala sanghian drains. The bacterial cultures exhibited removal even at higher levels of lead and the bacterial growth decreased with increase in the metal concentration. Similarly, sludge samples were analyzed for heavy metals. Nine different bacterial species were screened on the basis of morphological characteristics which grew in $10-50 \mathrm{mg} / \mathrm{l}$ of lead concentration. After screening, Pseudomonas aeruginosa was found capable to remove lead and used for further study. It showed consistent growth, both in nutrient broth and nutrient. The data was observed for the uptake of metal ions vs contact time for different conc. The metal removal efficiency increased with increase in time. However, a remarkably increased in percent lead removal was estimated $75.0 \pm$ $2.27 \%$ by Pseudomonas species. Different concentration of broth was used like $10 \mathrm{mg} / \mathrm{l}$, 
and $69.70 \pm 0.80 \%$ removal by Pseudomonas aeruginosa at 40mg/l and $90.88 \pm 0.87 \%$ by Pseudomonas aeruginosa. Pseudomonas aeruginosa removed considerable amount of lead and showed significant efficiency for bioremediation. From the above results it is observed that Pseudomonas aeruginosa can be used for the removal of lead from waste generated by industries. Further study can be carried out different concentrations and the strain can be selected for further removal of lead from effluent and sludge. $\mathrm{pH}$ of active sludge effluent was 8.0 and atmospheric temperature was $25^{\circ} \mathrm{C}$, while ambient temperature was $20^{\circ} \mathrm{C}$. Several mesophilic gram-negative and copper resistant bacteria were also isolated. The enrichment media showed better growth in comparison to direct culture method for the isolation of copper resistant bacteria and less time was taken by the organisms. Also, the isolates in primary enrichment method could grow on $6 \mathrm{mM}$ concentration of Copper containing medium.

Majority of the bacterial isolates were belonging to gram-negative non-fermentive Pseudomonas (4 isolates). One gram-negative coccus was also capable to grow on $2 \mathrm{mM}$ concentrations of Copper; but on subsequent inoculation, the strain lost its ability to grow on more than $2 \mathrm{ml}$ copper. The data obtained in this study clearly shows that with use of cadmium resistant mutated biomass, bioaccumulation of Copper solution considerably increased. P.aeruginosa one of the isolate was able to efficiently remove $94.7 \%$ in $30 \mathrm{mg} / \mathrm{L}$ of copper solution within 60 min. cadmium toxicity. Bio-chemical tests were performed to characterize microorganisms on basis of morphological and biochemical properties. The tests performed in the present study were Gram staining, Citrate utilization test, $\mathrm{H}_{2} \mathrm{~S}$ production, Nitrate reduction test, Indole test, Methyl red test, Voges-Proskaeur test.
It can be concluded from the present study "Bioremediation of Sludge using Pseudomonas aeruginosa Strain that Pseudomonas aeruginosa has great potential to remove the heavy metals like lead and copper from the sludge sample. The strain of Pseudomonas aeruginosa can be successfully used for the removal of lead, copper, cadmium and chromium. These bacteria were found very effectively in bioremediation of heavy metal because metals are directly and indirectly involved in the all aspect of microbial growth metabolism. Bioremediation of heavy metal by bacterial cell has been recognized as potential alternative to existing technologies for the removal of heavy metal from the industrial waste. This is an attempt to explore a new innovative, cost effective and environment friendly technology for the bioremediation of sludge containing heavy metals as contaminants by using microorganisms.

\section{References}

Chen J.M. and O.J. Hao, (1998), Microbial chromium (VI) reduction, Crit. Rev. Environ. Sci. Technol. 28 (3) 219-251

De la Cueva, S. C., Rodríguez, C. H., Cruz, N. O. S., Contreras, J. A. R., and Miranda, J. L. (2016). Changes in Bacterial Populations During Bioremediation of Soil Contaminated with Petroleum Hydrocarbons. Water, Air, and Soil Pollution, 227(3): 1-12.

Franchi, E., Agazzi, G., Rolli, E., Borin, S., Marasco, R., Chiaberge, S. and Barbafieri, M. (2016). Exploiting hydrocarbon-degrader indigenous bacteria for bioremediation and phytoremediation of a multi-contaminated soil. Chemical Engineering and Technology.

Ganguli, A. and A.K. Tripathi (2002), Bioremediation of toxic chromium from electroplating effluent by 
chromate-reducing Pseudomonas aeruginosa $\mathrm{A} 2 \mathrm{Chr}$ in two bioreactors. Appl. Microbiol. Biotechnol., 58, 416420.

Jardine, P.M. and D.L. Taylor (1995), Kinetics and mechanisms of Co (II) EDTA oxidation by pyrolusite. Geochim. Cosmochim. Acta., 59, 4193-4203.

Oleszkiewicz J. A. and Elektorowiz M. (1993) Groundwater contamination with trichloroethylene: the problem and some solutions. Journal of Soil Contamination 2(3), 205 \pm 228 .

Shen and Wang Y.T (1995), "Hexavalent chromium removal in two stage bioreactor system", J. Env. Engg., 11, 798-804.

Shiro Yoshizaki and Tahei Tomida. 2000. Principle and Process of Heavy Metal Removal from Sewage Sludge Environ. Sci. Technol., 2000, 34 (8), pp 1572-1575 DOI: $10.1021 / \mathrm{es} 990979 \mathrm{~s}$

Vidali M. (2001).Bioremediation. An overview. Pure Appl. chem. 73(7):1163-117

Zhang, F.-S., Nriagu, J. O. and Itoh, H. Mercury removal from water using activated carbons derived from organic sewage sludge. Water Res 39, 389-395 (2005).

\section{How to cite this article:}

Rajveer Kaur, Gurjot Kaur Mavi and Shweta Raghav. 2019. Bioremediation of Sludge using Pseudomonas aeruginosa. Int.J.Curr.Microbiol.App.Sci. 8(04): 69-79.

doi: https://doi.org/10.20546/ijcmas.2019.804.009 